\title{
ESTÉTICA DEL TIEMPO Y MOVIMIENTO EN EL POEMA «POR TIERRAS DE ESPAÑA»
}

VIRGINIA SANTOS-RIVERo

Yale University

\section{RESUMEN}

Por tierras de España expresa la realidad metafísica y existencial del hombre castellano. El poeta consigue mostrar el alma escéptica y agónica de los campos de Castilla, la cual infunde con los mismos atributos al hombre que los habita. De acuerdo con los postulados epistemológicos de la fenomenología, la poesía es el instrumento más adecuado para plasmar la realidad en el tiempo. Machado utiliza el tema —l alma de Castilla y de sus habitantes_ para captar la realidad externa, y la estructura — verso, tiempos verbales, ritmos, rimas, campos semánticos—para captar la realidad interna.

Para llegar a un acercamiento lo más puntual y fiel posible a las claves estéticas de la poesía de Machado debemos reflexionar primero sobre algunos aspectos que, si individualmente cada uno de ellos no condiciona su obra ni la caracteriza - como sería según algunos críticos su filiación a diferentes movimientos literarios: bien modernista bien noventayochista, o la tan debatida unidad de su obra—, sí que arrojan luz sobre algunos aspectos o facetas de su poesía, que viene delineada por ellos. 
La cronología de su vida y de su obra ya es de por sí un elemento harto esclarecedor: Machado vivió de 1875 a 1939, es decir, a caballo entre el siglo diecinueve y el veinte. El siglo diecinueve había experimentado la expansión y consecuencias del mayor cambio histórico producido desde las revoluciones neolíticas en la Prehistoria, esto es, la revolución industrial, cuyo efecto más inmediato y sobresaliente fue la aceleración de la historia y, consecuentemente, en el campo de las artes y del pensamiento, se produjo una sucesión de movimientos que, desde diversas posturas tratan de explicar e interpretar la nueva consciencia de la condición humana.

Así en pocos años se suceden el idealismo romántico alemán, el positivismo cientifista, y el marxismo por un lado, y, como contrapartida, el vitalismo, el historicismo, y el espiritualismo por otro. Con la conciencia de que una violenta y aguda crisis sacude al mundo, se desemboca en el siglo XX. Este sentimiento finisecular, generalizado en toda la cultura occidental, tiene su expresión característica en España, donde el año de 1898, con la pérdida de las últimas colonias ultramarinas, simboliza la «culminación» del proceso de decadencia que España había comenzado a sufrir desde finales del siglo XV. En palabras de Gullón, «es un periodo de revisión total, en el que nada, desde la teología hasta la geometría, deja de ponerse en duda, y el repudio de lo vigente se realiza sistemáticamente $\mathrm{y}$ a fondo.»

Dejaremos fuera de nuestro objetivo la cuestión de si Machado pertenece o no a la generación del noventa y ocho, que como señala Gullón, «no puede ser definida por el que varios escritores, desde perspectivas diferentes y con intenciones distintas, critiquen las estructuras sociales cuya insuficiencia padecen»; la consideración ética de lo estético se da en el 98 , sí, pero también tal circunstancia es epocal, no generacional, como es asímismo común a los escritores del modernismo en todos los países la disidencia y el choque con los poderes constituidos».

Pero sí señalaremos algunos aspectos de su biografía que podemos denominar circunstanciales, como lo son la filiación y estrecha relación de su familia con la Institución Libre de Enseñanza; su estancia en diversas ciudades castellanas, que le proporcionó un contacto directo con los habitantes de Castilla; el hecho de haber sido profesor de francés, lo cual le dio un conocimiento de primera mano de la poesía francesa; o su personal relación con la filosofía. Es precisamente esta relación con la filosofía el elemento que más determinantemente moldea y modela su poesía. Como señala Sánchez Barbudo,

«El gusto por la filosofía, por las lecturas filosóficas en general - y no sólo del Heidegger de segunda mano, también de Kant, Leibniz, Spinoza, Nietzsche, Schopenhauer, Bergson y otros que cita o parafra- 
sea-, llenó en la mente de Antonio Machado el hueco que produjeron escepticismos e incredulidades. Desde joven debió de sentir la imantación del pensamiento especulativo. Y pasados los años llegó a soñar una suerte de osmosis o intercambio entre ambas, mediante la cual habrían de trocarse los papeles entre poetas y filósofos»' (190-191)

En 1910, machado tomó un curso con Bergson en el Colegio de Francia: Henri Bergson muere en 1914, lo cual indica que cuando Machado estudia con él, sus teorías sobre la intuición como medio de conocimiento, así como el sentido de temporalidad cualitativa o «durée» ya estaban completamente desarrolladas y expuestas, las cuales influirán en el concepto y la teoría poética machadiana.

Con estos precedentes en el estudio de su obra, centraremos el foco de nuestra atención en la poesía Por tierras de España. Nos encontramos ante un poema perteneciente al libro Campos de Castilla, cuyo tema común es Castilla, siendo el del poema mencionado el retrato del hombre castellano. No se trata de un retrato individualizado, con nombres y apellidos, sino que es un retrato genérico del morador de esas tierras, el cual en un movimiento recíproco está condicionado, mediatizado y determinado por el paisaje castellano y es producto orgánico de él (los «páramos malditos»), y el cual a su vez tiene una incidencia inescapable en dicho paisaje, ya que es su habitante el que lo ha caracterizado y cincelado, lo ha humanizado modelándolo como un trozo de planeta apto para la sombra errante de Caín.

Parafraseando a Banco Aguinaga, «si algo ha quedado de la generación del 98 en la historia literaria recibida, ello ha sido precisamente su obra paisajista, metafísica, agónica, escéptica, existencial.» (95) ${ }^{2}$ Es claro que estos epítetos describen el poema Por tierras de España con precisión. Aunque es evidente el elemento paisajista en la descripción del hombre castellano como parte de su realidad metafísica, no se refleja sin embargo el amor a la naturaleza característico de tantos otros escritos tanto de Machado como de Unamuno, Azorín o Ganivet. Machado reflexiona sobre este tema en Juan de Mairena,

«¿Amor a la Naturaleza? Según se mire. El hombre moderno busca en el campo la soledad, cosa muy poco natural. Alguien dirá que se busca a sí mismo. Pero lo natural en el hombre es buscarse en su vecino, en su prójimo, como dice Unamuno... Más bien creo yo que el

\footnotetext{
I ANTONIO SANChez BARBUDO, «Las ideas filosoficas de Antonio Machado». Antonio Machado, Gullon y Phillips ed. Madrid: Taurus, 1979 (189-226).

2 Carlos Blanco Aguinaga, Juventud del 98. Barcelona: Crítica, 1978.
} 
hombre moderno huye de sí mismo, hacia las plantas y las piedras, por odio a su propia animalidad, que la ciudad exalta y corrompe.» (II, 47) ${ }^{3}$

Según esta interpretación del autor, cabría preguntarse si en el intento de plasmar la esencialidad del hombre castellano estaría Machado buscándose a sí mismo como participante del mismo paisanaje, aunque no necesariamente de los mismos atributos.

La decrepitud y decadencia del paisaje castellano tiene una conexión con la historia: el pasado histórico está ahí, y es éste de lo que el hombre español, de principios del siglo XX debe partir para construir su porvenir. Blanco Aguinaga apunta que

«La idea de la Tradición y la Naturaleza y de su relación con la Historia de los krausistas e institucionalistas difiere de los tradicionalistas, naturalistas y paisajistas que tienden al "menosprecio de corte y alabanza de aldea", como Femán Caballero, Pereda o Trueba... Sin embargo su visión de la naturaleza (de los institucionalistas) es ambigua.» (123) ${ }^{4}$

La consciencia histórica se sintetiza en la decrepitud y decadencia moral y espiritual que tiene sus raíces en el pasado, pero que condiciona y aplasta el presente. La que nos muestra Machado en Por tierras de España es una visión negativa y sin esperanza de Castilla, y por extensión de España, ya que es el hombre, su habitante, el que al aniquilar al vecino y a la vegetación, se destruye a sí mismo sistemáticamente, y el que destruye el paisaje, al que sólo le queda un vacío desolador que es reflejo patético de su alma. Este es el punto de enlace del poeta con su circunstancia nacional, cuya culminación del proceso de destrucción fratricida habría de sufrir Machado años después al final de su vida.

Desde la primera línea de Por tierras de España nos expone la naturaleza destructiva del campesino castellano, que entra en escena incendiando pinares, acción exterminadora donde las haya, de lo cual obtiene un despojo de manera violenta como en la guerra, y que anteriormente ha raído y talado los árboles, otras dos operaciones vehementes y devastadoras. Así el hombre incendia, despoja, rae y tala los pinares, los encinares y los robledos de la sierra; efecto del hombre sobre la naturaleza: paisaje humano.

Lo que hoy permanece, la herencia que del campo recibe este hombre es la pobreza, la huida de los vástagos y con ella la condena a la falta de fertilidad y de hogar; queda la tempestad, el elemento de la naturaleza que continúa

\footnotetext{
${ }^{3}$ Antono Machado, Juan de Mairena. Ed. Antonio Fernández Ferrer. Madrid: Cátedra, 1986.

4 Carlos Blanco Aguinaga, Juventud del 98. Barcelona: Crítica, 1978.
} 
la obra de devastación del paisaje. Se destruye la tierra fértil, llevándosela hacia los mares —elemento ausente del paisaje castellano-, quedando los páramos, símbolo de la miseria de la región, y estando malditos para sus habitantes, ya que mientras sea éste el prototipo del hombre que lo habita, está sentenciado a la desolación planetaria, ya que es él mismo quien la causa. Por eso está condenado a trabajar, sufrir y errar (en su doble sentido de equivocarse y de vagar sin rumbo fijo).

En la tercera estrofa nos habla del antecedente del castellano: su característica es la transhumancia, estadio de la evolución de la cultura humana de resabios bíblicos: Abel, pastor, fué asesinado por la envidia de Caín, agricultor. Está implícita una valoración del pasado, que aunque primitivo — «rudos caminantes»-, no era maldito, sino que sugiere la riqueza y prosperidad de los tiempos en los que la Mesta proporcionaba abundancia y prodigalidad a Castilla, lo cual se refuerza con la idea de fertilidad de otra tierra, Extremadura, y con la imagen de ensueño del sol dorando los rebaños. La descripción física que hace a continuación en la cuarta estrofa, podría perfectamente corresponder a la de un animal enjaulado, cuyo rasgo humanoide son sus ojos recelosos, y cuya facción más sobresaliente son, en metáfora de reminiscencias pretrarquianas, las muy pobladas cejas; atributos corporales en los que está ausente cualquier asomo de inteligencia, de raciocinio o de conciencia.

Y si éste es el cuerpo, el alma no es mucho más aventajada, ya que escondida debajo del «pardo sayo», como un asesino al acecho de su víctima, no sólo vive en servidumbre de todos y cada uno de los siete pecados capitales, sino que aloja «vicios insanos» y «crímenes bestiales», como aquellos escabrosos e inimaginables tradicionalmente relatados por los ciegos de pueblo en pueblo, que le degradan a la categoría animal por lo inexcusables y que tiene su materialización más genuina en el fratricidio de maldición bíblica. El estado de ánimo de esta criatura habitante de los campos de Castilla siempre está envenenado con la envidia o la tristeza, la rueda de la fortuna nunca le es favorable, ni siquiera cuando alcanza lo que más anhela, la riqueza: lo bueno y lo malo tienen un doble efecto demoledor en él: ambos le hieren y acongojan.

De este retrato psicológico, pasamos sin solución de continuidad a la descripción del numen, el carácter o el alma de estos campos, y éste es el reflejo espiritual del alma del campesino: consecuentemente es sanguinario y fiero; el paisaje mismo está impregnado de figuras guerreras: el centauro sobre el alcor, llanuras bélicas, tierras para el águila, espacio planetario para la sombra errante de Caín; paisaje que es la antítesis extrema del bíblico jardín, o sea; un infierno en la tierra.

El espacio que representa en este poema, el ámbito de la realidad es la tierra castellana. Sin embargo, éste no es un «espacio puramente lírico inventado 
por el poeta para situar las formas del poema», como lo quiere Gullón, sino que corresponde al intento del poeta para penetrar en la misma entraña de lo real, para lo cual la observación empírica de cuño naturalista, es decir, la inteligencia, no sirve. El único instrumento con el que cuenta para sumergirse en la médula de la realidad, es la intuición.

Según la filosofía bergsoniana, basada en el concepto del «élan vital», la intuición es una simpatía por la que penetramos en el interior de lo real, de las cosas, captando su mismidad. Esta intuición no es comunicable, sino que el que la experimenta capta lo real, pero al ser lo captado inefable, no puede comunicarlo directamente, ya que el lenguaje humano es conceptual, es un producto de la inteligencia. La intuición, por tanto, es incomunicable, pero puede sugerirse mediante imágenes; de ahí que la poesía sea uno de los vehículos más adecuados para conocer y expresar la realidad.

El tema del poema, el hombre castellano, trata de asir con esa intuición poética la realidad eterna del alma española, de la que se erige en símbolo. No es simplemente un contexto literario, sino que la poesía, por su capacidad de captar la palabra en el tiempo, es el instrumento adecuado para expresar la verdad del paisaje castellano, que finalmente expresa en un contexto histórico y político que lo determina, la esencia del hombre español.

Sánchez Barbudo lo ha apuntado con palabras del propio Machado:

«Lo que Machado había escrito en el apéndice en cuanto al poeta y las apariencias, lo repite en Juan de Mairena: «El filósofo puede dudar de la realidad del mundo externo, pero el poeta no, ya que "nadie duda de lo que ve, sino de lo que piensa"” y para el poeta sólo hay "ver". Por eso la poesía es "un acto vidente, de afirmación de una realidad absoluta, porque el poeta cree siempre en lo que ve"» (197-98) ${ }^{5}$.

Ciertamente, la definición de poesía de Machado es clara en este sentido: se mueve en una coordenada temporal en la cual es captado el objeto poético en un gesto instantáneo que va a ser lo que permita al poeta eternizarlo: «la poesía es el diálogo de un hombre con su tiempo. Eso es lo que el poeta pretende eternizar, sacándolo de fuera del tiempo», y con una metáfora, nos explica que «El poeta es un pescador, no de peces, sino de pescados vivos, de peces que puedan vivir después de pescados». En el acto de escribir la poesía y captar por medio de la intuición la esencia vital de las cosas por medio de imágenes, el poeta crea una nueva entidad que es la obra poética, y a la vez eterniza la faceta esencial de lo cantado que como hombre le ha sido revelado en el diálogo con su conciencia del tiempo, produciendo algo nuevo y vivo: crea una nueva realidad artística.

5 Antonio SÁnChez BARBUdo, «Ideas filosóficas de Antonio Machado». Antonio Machado, Gullón y Phillips ed. Madrid: Taurus, 1979 (189-226). 
La capacidad de la poesía de captar lo temporal es un elemento que Machado admira: por ello, elogia dentro de la literatura española las Coplas de Manrique, el Romancero y parte de la obra de Bécquer, ya que en ellas se capta y se fija una intuición poética vivida, mientras que desdeña la poesía del Siglo de Oro «puesto que emplea "conceptos e imágenes conceptuales", pensadas, no intuida, - situadas "fuera del tiempo psíquico del poeta", de lo captado y vivido por su propia conciencia-», cuyo prototipo sería el famoso Soneto a las flores de Calderón.

Su interpretación de la poesía es de neta filiación bergsoniana, con una doble perspectiva del tiempo. López-Morillas señala muy acertadamente que « el interés de Machado por el tiempo no está fuera de lugar en una época caracterizada por el propósito anhelante de hallar en el tiempo la fundamentación de una nueva metafísica» $(260)^{6}$. Y efectivamente, no es dificíl imaginar el efecto que la aceleración de la historia característica del siglo XIX a la que aludimos anteriormente tuvo en la psicología del hombre occidental, que desemboca en el existencialismo, y que el mismo Machado atribuye a lo que él llama la «angustia del tiempo», que hace cantar al poeta,

«Porque, ¿cantaría el poeta sin la angustia del tiempo, sin esa fatalidad de que las cosas no sean para nosotros, como para Dios, todas a la par, sino dispuestas en serie y encartuchadas como balas de rifle, para dispararlas una tras otra? Que hayamos de esperar a que se fría un huevo, a que se abra una puerta o a que madure un pepino, es algo, señores, que merece nuestra reflexión... Vivir es devorar tiempo: esperar... Ya en otra ocasión definiríamos la poesía como diálogo del hombre con su tiempo... la poesía es palabra en el tiempo...» $(I, 32){ }^{7}$.

Lo que Pérez Firmat señala como propio de la poesía de las ruinas, tiene un paralelismo en el espacio poético que aquí se representa: el campo castellano con sus moradores, el cual (como las ruinas), «tiene una particular relación con el tiempo, ya que es evidencia de la acción marchitadora del tiempo y de la resistencia a la decadencia temporal. Porque la ruina sucumbe al paso del tiempo, a la vez que sobrevive; es uno de los símbolos más ambiguos de los usados por Machado para expresar la temporalidad.» [«has a peculiar relation to time, for it is evidence of both time's withering action and of the resistance to temporal decay. Because (the ruin) both succumbs to and survives the ravages of time, it is a more ambiguous symbol than many others also employed by Machado to express temporality] (53) ${ }^{8}$.

- JUAN LÓPEZ-MORILlAS, «Antonio Machado y la interpretación temporal de la poesía». Antonio Machado. Gullón y Phillips ed. Madrid: Taurus, 1979 (251-266).

7 Antonio MaChaDo, Juan de Mairena. Ed. Antonio Fernández Ferrer. Madrid: Cátedra, 1986

8 Gustavo Pérez Firmat, «Machado and the Poetry of Ruins». Hispanic Review. Vol 56, N. 1. Philadelphia: University of Pennsylvania, 1988. 
Para Bergson, la inteligencia parte ordinariamente de lo inmóvil, y, como puede, reconstruye el movimiento con inmovilidades yuxtapuestas. La intuición, sin embargo, parte del movimiento y lo percibe como la realidad misma, no viendo en la inmovilidad sino un momento abstracto, instantáneo, tomando por nuestro espíritu sobre una movilidad. La realidad entera es puro devenir. Es una filosofía de fuerte parentesco heraclitano: todo fluye en el impulso vital.

La estructura y disposición del poema sirve magistralmente de contrapunto a esta captación intuitiva del hombre castellano que Machado nos da en Por tierras de España. Si el tema y lo que sobre él expresa el poeta nos da la dimensión temporal externa del poema, la estructura propiamente dicha nos da la dimensión temporal interna. Nos referimos a los elementos técnicos de valor estético, instrumentos que el poeta maneja con harta destreza, siendo éstos por una parte la versificación, y dentro de ella la distribución de sintaxis y recursos poéticos, que definen el ritmo del poema, y por otra, el uso del lenguaje.

El tipo de versificación que utiliza es el verso épico de catorce sílabas, dividido en dos hemistiquios de siete por una pausa o cesura, en ocho estrofas de cuatro versos cada una y con rimas en consonante con la distribución ABAB. Ya Lope había señalado en su Arte nuevo de hacer comedias cómo cada tipo de verso corresponde a la expresión de un estado de ánimo diferente. El tono invariable y monótono es uno de los rasgos de toda la poesía de Machado. Gerardo Diego llama tempo o andadura a este ritmo interno del verso, el cual

«en los alejandrinos suele ser monótona y pesada; la acentuación no obligatoria suele recaer con frecuencia en la misma sílaba, por ejemplo en la segunda después de cada hemistiquio en los alejandrinos, lo que es da un curioso parentesco con los de los románticos» (269) ${ }^{9}$.

Si trazamos el esquema de las acentuaciones de las palabras como si de un ejercicio musical se tratase, la estructura rítmica se nos revela equilibrada, de suaves y monótonas modulaciones y con una repetitividad fluida. En la transcripción rítmica que se ofrece a continuación,

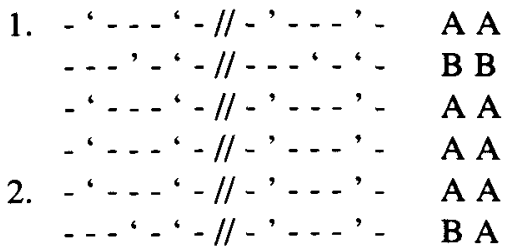

9 Gerardo Diego, «Tempo lento en Antonio Machado». Antonio Machado. Gullón y Phillips ed. Madrid: Taurus, 1979 (267-272). 


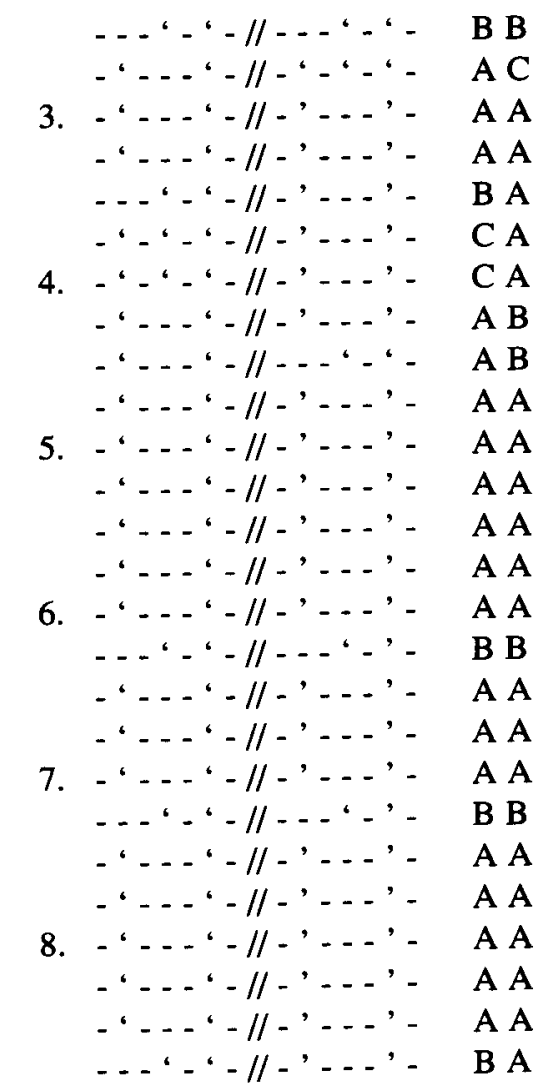

donde el guión representa una sílaba no acentuada; la tilde una sílaba acentuada y dos líneas // la pausa entre hemistiquios, se hacen evidentes estas características.

Utiliza tres tipos de distribución de los acentos dentro de cada hemistiquio, que hemos llamado A (-'---'-), B (---'-'), y C (-'-'-'), y que corresponden a las letras situadas al final de cada verso en el esquema de la página anterior. Nos encontramos aquí con un instrumento artístico en la creación del lenguaje poético que es el melódico, con el que se va a expresar no sólo el color musical, sino el estado de ánimo del poema: uniformidad del tono, reiterado y condenado a reproducirse y a transportarse, como la maldición bíblica de Caín, hasta la eternidad. El repiqueteo monódico redunda en el sentimiento de monotonía interminable y de maldición ineludible.

De estos tres tipos, A, y C son simétricos, y B es asimétrico, tendiendo a enfatizar las cuatro últimas sílabas: el poema se modula en su mayor parte según el 
tipo A, y la estructura B se utiliza a manera de contrapunto, de forma escasa y esparciéndola a lo largo del poema como contraste con el balance equilibrado de A. La estructura $C$ la utiliza en tres ocasiones: en el caso de los versos 8 y 9 , al combinarla con tríos de adjetivos, enfatiza la repetición inherente e inescapable que expresa respectivamente el presente del castellano: «trabaja, sufre y yerra» y sus características físicas deshumanizadas: «Pequeño, ágil, sufrido».

La uniformidad melódica se ve contrastada por la variedad de las rimas de distribución ABAB como anteriormente se ha señalado-, que sobreimpone una diversidad fónica sobre el fondo rítmico plano, y que con excepción de la segunda estrofa, donde se repiten las de la primera para captar la atención del lector y hacerle sentir familiar con su sonido, en cada estrofa a partir de la tercera se nos obsequia con dos tipos de rima nuevos, llegando a contarse hasta catorce rimas diferentes. El esquema de las rimas se conforma de la siguiente manera: ABAB, ABAB, CDCD, EFEF, GHGH, IJJ, KLKL, y MNMN.

Para captar y expresar un momento cualquiera en el devenir del tiempo, que represente todos los momentos de la duración de la vida de que habla Bergson, Machado utiliza en este poema de manera casi absoluta el presente de indicativo. Si bien en su concepto «el verso temporal por excelencia es -como en el Romancero- en -ía», el presente lo utiliza para expresar de manera metafísica tanto acciones del pasado: pastores que «conducen» sus hordas de merinos, como del presente: «ve» a sus hijos, como de futuro: «trabaja», «sufre» y «yerra». También expresa con este tiempo verbal atemporalidad, al describir las características físicas y psicológicas: éstas son su esencia, lo eterno castellano.

Dos pretéritos pluscuamperfectos — «hubo raído», «hubo talado»- nos remiten al origen del pecado del hombre castellano, y a un remoto pasado al que no es posible volver pues se ha extinguido, aunque la sombra de su acción cercenadora sigue pesando sobre su existencia y es su realidad cotidiana. Sólo cuando el autor se dirige, apela directamente al lector, la coordenada temporal varía: «veréis» se sale de la duración constante de la esencia castellana para señalar una acción y un agente ajenos a ella, y que, en violento contraste con la inexorabilidad de la realidad de los campos de Castilla, es fruto de una acción voluntaria del lector $\mathrm{y}$, por tanto, contingente.

Como afirma de la Iglesia, «Machado nunca se está refiriendo al tiempo mecánico y espacializado de la física, medido por los relojes, sino al tiempo existencial. Este último, distinto del primero, es subjetivo, cualitativo...» (89) ${ }^{10}$, el tiempo cronológico no tiene pues cabida en este poema, sino el tiempo psicológico que su espíritu experimenta como vivencia.

10 José LuIS de la IGlesia et al., Antonio Machado y la filosofía. Madrid: Orígenes, 1981. 
En cuanto al uso del lenguaje, el autor se muestra extremadamente preocupado por las implicaciones que el servirse de un tal material acarrea para la consecución de sus propósitos estéticos; como el mismo Machado nos recuerda:

«El material que el lírico maneja es la palabra. La palabra no es materia bruta ...(El poeta) ha de ver (en ella) ... lo que puede ser mero sustentáculo de un mundo ideal; materia no elaborada, en suma.... Las palabras, a diferencia de las piedras, maderas, o metales, son ya por sí mismas significaciones humanas, a las cuales da el poeta, necesariamente, otra significación» (37) ${ }^{11}$.

El uso que hace de ese material plástico que son las palabras, viene definido por boca de Mairena: «Lo clásico es el empleo del sustantivo, acompañado de un adjetivo definidor.» Los calificadores que usa: «pobre», «malditos», «rudos», «sufrido», «hundidos», «recelosos», «malo», «insanos», «bestiales», «pardo», «fea», «esclava», «turbios», «sanguinario», «fiero», «bélicas», «errante», aunque un denominador común de profunda negatividad y pesimismo, se pueden agrupar en cuatro campos semánticos: el primero nos describe su circunstancia, la carencia o escasez, miseria, ruina, desgracia, que soporta con pasividad y le convierte en víctima de sí mismo, por lo que está naufragado y destruido, enterrado en su desdicha; el segundo nos habla de los atributos de su alma: aborrecible, blasfema, execrable, debido a su desconfianza e incredulidad, lo que le hace un ser defectuoso, imperfecto, de corrupción perversa y morbosa crueldad, su fealdad espiritual alcanza proporciones deformes y monstruosas; el tercero se refiere a la deshumanización de su personalidad, ya que es tosco y agreste, rozando lo salvaje, que vive en estadio servil por lo que no alcanza la plenitud humana del ciudadano de derecho, con una violencia perversa y un afán vengativo y sangriento que radica en su envidia y que tiene como consecuencia crueles guerras y feroces agresiones al medio natural y a sus semejantes; y finalmente, el cuarto grupo se refiere a una cualidad plástica que dimana de los anteriores, y se relaciona con el color pardo, sin timbre claro, y con la turbiedad y confusión de su espíritu, vagabundo en los desolados parajes de los páramos castellanos.

A nivel sintáctico, Machado construye una arquitectura de la que se sirve como material expresivo; así utiliza los hemistiquios como unidades gramaticales, $y$ en ellos instala unidades sintácticas a la manera de bloques para edificar el poema, comenzando después de la pausa, complementos directos, circunstanciales, o partitivos, así como sujetos o yuxtaposiciones enlazadas con comas o conjunciones. Sin romper esta distribución, en ocasiones la altera, con un efecto enfático, como en los versos 8 y 13, donde el ritmo ternario viene dado por la yuxtaposición de tres verbos y tres adjetivos respectivamente;

"Antonio Machado, Los complementarios. Ed. Manuel Alvar. Madrid: Cátedra, 1982. 
ya vimos como es en estos mismos versos donde el ritmo de la acentuación es también diferente. O utiliza la repetición de una estructura paralela con un efecto acumulativo y multiplicador de los significados, como en el verso 24 . Ocasionalmente hace uso del encabalgamiento, que en ningún momento interfiere con el equilibrio de la construcción.

A lo largo de este trabajo hemos visto cómo la estética de Machado esta intrínsecamente entrelazada con su concepción metafísica del objeto poético, y cómo los recursos poéticos o técnicas artísticas utilizadas magistralmente por el poeta, convergen en la expresión de esa angustia temporal del hombre castellano; «lo que pasa en Castilla» - parafraseando la famosa frase de Mairena «lo que pasa en la calle»— queda plasmado en estas ocho estrofas con una serena y honda belleza que no surge del tema tratado, sino de ese "pescado vivo» que Machado nos ofrece, y que es el poema en sí mismo, cuyo valor extraliterario más significante es apuntar y revelar certeramente ese trozo de la realidad española que es el hombre de los campos de Castilla.

\section{ObRas CONSULTADas}

AGUIRRE, J. M. (1973): Antonio Machado, poeta simbolista. Madrid: Taurus. Blanco Aguinaga, Carlos (1978): Juventud del 98. Barcelona: Crítica.

Díaz-PlaJA, Guillermo (1979): Modernismo frente a Noventa y Ocho. Madrid: Espasa-Calpe, 1979

DiEGo, Gerardo (1979): «Tempo lento en Antonio Machado.» Antonio Machado. Gullon y Phillips ed. Madrid: Taurus (267-272).

FERrater Mora, José (1980): Diccionario de filosofia. Buenos Aires: Sudamericana. Gicovate, Bernardo (1979): «La evolución poética de Antonio Machado». Antonio Machado, Gullón y Phillips ed. Madrid: Taurus (243-250).

GuLLón, Ricardo (1969). La invención del 98 y otros ensayos. Madrid: Gredos.

- (1986): Una poética para Antonio Machado. Madrid: Espasa-Calpe.

DE LA IGLESIA, José Luis et al. (1981): Antonio Machado y la filosofía. Madrid: Orígenes.

Lafin Entralgo, Pedro (1970): La generación del noventa y ocho. Madrid: EspasaCalpe.

LOPEZ-MORILLAS, Juan (1979): «Antonio Machado y la interpretación temporal de la poesía». Antonio Machado. Gullón y Phillips ed. Madrid: Taurus (251-266).

MaCHADO, Antonio (1982): Los complementarios. Ed. Manuel Alvar. Madrid: Cátedra.

- (1986): Juan de Mairena. Ed. Antonio Fernández Ferrer. Madrid: Cátedra.

- (1977): Poesías completas. Ed. Manuel Alvar. Madrid: Espasa-Calpe. 
Navarro TOMÁs, Tomás (1979): «La versificación de Antonio Machado». Antonio Machado. Gullón y Phillips ed. Madrid: Taurus (273-291).

Pérez Firmat, Gustavo (1988): «Machado and the Poetry of Ruins». Hispanic Review, vol 56, N. 1. Philadelphia: University of Pennsylvania (1-16).

Preminger, et al. (1974): Princeton Encyclopedia of poetics and poetry. Princeton: Princeton University Press.

SÁNCHEZ BARBUDO, Antonio (1979): «Ideas filosóficas de Antonio Machado». Antonio Machado, Gullón y Phillips ed. Madrid: Taurus (189-226).

- (1974): El pensamiento de Antonio Machado. Madrid: Guadarrama.

DE TORRE, Guillermo (1979): «Teorías literarias de Antonio Machado». Antonio Machado, Gullón y Phillips ed. Madrid: Taurus (227-242). 